\title{
Taxation of a venture capitalist with a portfolio of firms
}

\author{
By Christian Keuschnigg
}

University of St. Gallen (IFF-HSG), Varnbuelstrasse 19, CH-9000 St. Gallen, Switzerland; e-mail: Christian.Keuschnigg@unisg.ch

\begin{abstract}
Venture capitalists not only finance but also advise and thereby add value to young entrepreneurial firms. The prospects of venture capital backed firms thus depend on joint efforts of entrepreneurs and informed venture capitalists, and are subject to double moral hazard. For this reason, managerial support and the number of portfolio companies tend to be inefficiently low. This paper investigates how tax policy can possibly contribute to a more active style of venture capital investments. An optimal tax policy is derived that moves the private equilibrium towards a first best allocation.
\end{abstract}

\section{Introduction}

Young entrepreneurial firms are an important source of innovation driven growth. Researchers and developers often find it more promising and rewarding to set up their own small company to promote and commercialize new ideas for potential products and services. In case of success, the financial reward tends to be large. On the other hand, the technological, commercial, and managerial risks of starting a young technology company are daunting. Bringing a new business idea to production stage and adapting it to special customer needs usually requires extensive further research and development with its own risks and uncertainties. When new markets are targeted, it is far from sure that the new product or service will eventually appeal to customers. Running and managing a young technology company and building its human resource base confronts aspiring entrepreneurs with entirely new challenges to which they are often ill prepared. Finally, their own resources are typically quite limited, compared to the capital needs of a fast growing technology company. They must attract outside risk capital. In short, entrepreneurs have ideas but lack capital as well as commercial experience.

Venture Capitalists (VCs) are specialized in financing young, innovative firms. They provide not only finance but also valuable business advice. ${ }^{1}$ In doing so, they draw on their own extensive business experience and detailed industry knowledge

\footnotetext{
${ }^{1}$ Kaplan and Strömberg (2001) describe the main functions of VC financing which consist of screening, contracting and advising.
} 
which banks or other financial intermediaries do not have. Given their commercial expertise, VCs are in a position to add value to young companies in making them grow faster and larger. They help in establishing customer and supplier contacts, attracting key personnel and giving strategic business advice. For this reason, a healthy VC sector is often considered an important institutional factor for technology driven growth. There is considerable empirical evidence which points to the VCs' important role in the professionalization of young firms. Hellmann and Puri (2002) show empirically that VC backed start-ups in Silicon Valley are much faster in introducing stock option plans for high skilled personnel and in hiring a professional sales manager. Also, the presence of a VC makes it more likely that the entrepreneur is replaced by a professional CEO from outside if her lack of managerial abilities turns out to be an impediment to the firm's rapid growth. Hellmann and Puri (2000) find that VC backed firms introduce more radical innovations and pursue more aggressive market strategies than other start-ups. For example, once a VC joins the firm, the probability of introducing the new product on the market jumps up by a factor of more than three! Rapid market introduction is strategically important because the first firm enjoys a first mover advantage. According to Kortum and Lerner (2000), a dollar of R\&D spending creates more patents and more radical innovations than the same expenditure in other firms. They calculate that VC backed firms account for about $14 \%$ of industrial innovation in the US in 1998 although they spend only about 3\% of all R\&D funds. VC can thus significantly promote innovation and business growth.

It is clear that the VC's support activities are rather time consuming, and time is a VC's scarcest resource. For this reason, and in contrast to banks, VCs advise and fund only a rather limited number of companies. According to the empirical evidence collected in Kaplan and Strömberg (2003) for the US, Cumming (2001a) for Canada, and Cumming (2002) for Europe, a typical VC portfolio includes between 10 and 20 firms, or even fewer. Larger portfolios are often indicating problems with the quality of those VC funds. ${ }^{2}$ Such small numbers point to an important trade-off between portfolio size and extent of involvement with individual portfolio companies. To promote innovation and growth among start-up firms, VCs by definition must make a real contribution and must closely work together with their portfolio companies. Obviously, close involvement and intensive managerial support requires to focus on a small number of firms. On the other hand, when the investment know-how and reputation of experienced VCs are in scarce supply and not easily acquired by new VC funds, ${ }^{3}$ then an increasing

\footnotetext{
${ }^{2}$ Cumming (2001a) and Cumming and MacIntosh (2002) found that Canadian Labour Sponsored Venture Capital Funds (LSVCCs) typically finance much larger portfolios of up to 60 firms but have systematically underperformed compared to other private VC funds.

${ }^{3}$ Gompers and Lerner (1999, p.4) emphasize that 'the skills needed for successful venture capital investing are difficult and time-consuming to acquire'. Cumming and MacIntosh (2002) argue that the lack of specialized managerial skills and training on the part of LSVCC managers is a principal reason for the underperformance of these funds.
} 
demand for VC support by start-up entrepreneurs can be accommodated only if established funds expand their portfolios. Optimal portfolio size and extent of managerial advice are then two key, interrelated factors that may importantly determine the potential of a country's VC sector to be a driver of innovation and growth. It is therefore of prime importance to ask which factors shape the trade-off between portfolio size and extent of VC involvement with start-up companies.

The availability of high quality VC is probably still a considerable bottleneck especially in Europe. Comparing econometrically the performance of VC backed and other young firms listed on the Euro.nm stock markets, Bottazzi and Da Rin (2002) found that European VCs had little effect on growth, corporate strategy and job creation of their portfolio firms. Their results indicate that 'the quality of European venture capital might be a more urgent issue than its sheer quantity'. From a policy perspective, the key question is whether the VC industry itself is able to resolve the incentive problems in an efficient way. If not, what is the role of economic policy in helping to develop more efficient investment patterns?

This paper asks whether the capital gains tax impairs VC performance, and whether tax policy could be reformed to foster a more active VC industry. Poterba (1989) and Gompers and Lerner (1998) found that the capital gains tax mainly affects the entrepreneurs' tendency to start a firm and thereby influences the demand for funds while it has only a minor effect on the supply of funds. This work is empirical and has not spelled out the microfoundations of VC finance. Gordon (1998) also discusses the effects of taxes on the entrepreneur's occupational choice decision and shortly investigates informational problems relating to VC finance but does not explicitly consider the VC's productive role in supporting and advising a portfolio of start-up firms. Except for Keuschnigg and Nielsen (2001, 2003, 2004), a detailed analysis of the taxation of VC is missing in the public finance literature. ${ }^{4}$ Having assumed linear effort costs, these authors could not explicitly consider issues related to optimal portfolio size and the interaction with the extent of managerial support as in this paper.

Kanniainen and Keuschnigg (2003) have introduced the concept of an optimal VC portfolio and pointed to a fundamental trade-off between portfolio size and the degree of VC involvement. Larger portfolios tend to undermine the quality of advice. Kanniainen and Keuschnigg (2002) have embedded this framework within an industry model that also endogenizes venture returns. They show how the industry responds to various demand and supply side shocks.

\footnotetext{
${ }^{4}$ Keuschnigg and Nielsen $(2001,2003)$ considered the implications of moral hazard and risk aversion by entrepreneurs but assumed precommitment, and thereby excluded moral hazard, on the part of VCs. They found that small taxes involve no welfare losses to the first order. In particular, government insurance via the tax transfer system cannot raise welfare when private parties agree on optimal risk sharing to provide incentives for entrepreneurial effort. Keuschnigg and Nielsen (2004) turn to the case with double moral hazard in a world of risk neutrality and find that effort tends to be inefficiently low. This feature is shared by the present paper as well.
} 
Apart from the descriptive analysis of industry equilibrium, these authors also found that both managerial advice and portfolio size tend to be inefficiently low in private equilibrium. They have not investigated whether tax policy could sharpen incentives and potentially help to foster a more active style of VC investing. An analysis of the role of tax policy towards VC investment, including its impact on the quality versus quantity trade-off, is left to the present paper.

The present paper is an application of the basic framework introduced by Kanniainen and Keuschnigg $(2002,2003)$ which, in turn, is importantly inspired by recent theoretical literature on VC finance. This literature emphasizes contractual problems due to the presence of double moral hazard that arises when the success of young technology firms must rely on the joint efforts of both entrepreneurs and VCs. ${ }^{5}$ Although the theoretical literature on VC is by now quite large, I know of no contribution other than Kanniainen and Keuschnigg (2002, 2003) that explicitly formalizes an optimal VC portfolio of firms which is an obvious stylized fact in VC finance. There is no other paper which considers the impact of taxation on the trade-off between advice and portfolio size, or even touches the question of optimal taxation in this framework. ${ }^{6}$

Section 2 now presents the model of a VC with a portfolio of firms where VC investing is subject to a capital gains tax and a start-up tax or subsidy. Section 3 considers the efficiency of the private equilibrium and finds that managerial advice and portfolio size are distorted. ${ }^{7}$ It turns out that both advice and portfolio size tend to be too small in private equilibrium. Tax incidence is discussed and an optimal policy is derived which importantly depends on the trade-off in VC investing between managerial advice per firm and overall size of the company portfolio. The optimal policy calls for a performance related revenue subsidy, i.e. a negative capital gains tax, to boost advice. However, if not complemented by a tax on startup investment cost, this subsidy would at the same time lead VCs to finance too many companies which would again crowd out advice per firm. The revenue subsidy must thus be combined with a tax on start-up investment cost to arrive at a more moderate net subsidy per project. Only this combined package succeeds to strengthen advice and to expand VC portfolios in the right amount. Section 4 shortly compares these findings with actual taxation of the VC industry in Europe and concludes with some final comments.

\footnotetext{
${ }^{5}$ The literature is quite proliferate. See Holmström (1982), Aghion and Tirole (1994), Bergemann and Hege (1998), Hellmann (1998), Neher (1999), Repullo and Suarez (1999), Lülfesmann (2001), Casamatta (2003), Inderst and Müller (2003), Schmidt (2003), and Cornelli and Yosha (2003) for a few important, but by no means complete references. The present model is in fact quite stylized and reduces the relation between a VC and entrepreneur to a static one rather than allowing for sequential investments, staging, renegotiation and other refinements.

${ }^{6}$ Note that Keuschnigg and Nielsen have not dealt with the interaction of portfolio size and advice.

${ }^{7}$ The efficiency criterion is the joint surplus derived from a VC fund that is shared by the VC, the startup entrepreneurs, and the government. In focusing on the investment process, we cut out any potential welfare gains that might results from the contribution of new firms to innovation.
} 


\section{The model}

\subsection{Venture capital activity}

Entrepreneurs have ideas but lack own resources as well as commercial experience. VCs have money and business experience. They finance and advise a portfolio of firms. Starting a firm requires a fixed capital expenditure $I$. Start-up investment is risky, i.e. the value of the firm is $V$ if successful but nothing if it fails. To make it a success, the entrepreneur contributes the technological idea and her research effort $e_{i}$ while the VC supports the venture with valuable business advice $a_{i}$. Since she finances a portfolio of $n$ firms, she must expend a total amount of consulting activity, or advice, equal to $A=\sum_{i} a_{i}=a n{ }^{8}$ An entrepreneur and a VC jointly contribute to the success probability of the firm. We assume, however, that the entrepreneur's effort is critical, i.e. the firm can never succeed without it. While the VC's advice per firm is more of a gradual matter, the entrepreneur's effort is therefore all or nothing, $e_{i} \in\{0,1\} .^{9}$ The critical nature of the entrepreneurial input is reflected in the specification $P\left(e_{i}, a_{i}\right)=e_{i} \cdot p\left(a_{i}\right)$ of the success probability. VC advice is subject to decreasing returns to scale in each firm, $p^{\prime}\left(a_{i}\right)>0>p^{\prime \prime}\left(a_{i}\right)$. Given the discrete nature of the entrepreneur's input, her effort cost is $l\left(e_{i}\right) \in\{0, \beta\}$. The VC's cost $c(A)$, in contrast, is variable and increases progressively with her overall managerial effort that is expended in advising the entire portfolio of firms. The following, isoelastic specifications further simplify the analysis

$$
\left[P\left(e_{i}, a_{i}\right)=e_{i} \cdot p\left(a_{i}\right), \quad p(a)=\frac{a^{1-\theta}}{1-\theta}, \quad c(A)=\gamma \frac{A^{1+\varepsilon}}{1+\varepsilon}, \quad \gamma, \varepsilon>0, \quad 0<\theta<1\right]
$$

VC investing involves the following sequence of events. First, the government sets tax policy. Second, the VC decides upon the size of her portfolio and, accordingly, selects a number $n$ of firms. ${ }^{10}$ Third, the VC proposes to entrepreneur $i$ to buy a stake $1-s_{i}$ in the firm at a price $Q_{i}$. The entrepreneur accepts the offer and starts the firm, or else stays with her outside option that pays a wage $w$ in industry. Fourth, after the deal is struck, the VC and the entrepreneur simultaneously expend effort to advance the success prospects of the firm. Efforts are assumed not to be verifiable and are therefore not contractible. Effort costs are intangible. Finally, nature rewards effort with success or failure. In case of success, venture returns $V$ are shared according to the terms of the contract.

The returns to VC investing mostly accrue as capital gains rather than dividends. We focus solely on the taxation of VC firms and consider a capital gains tax at

\footnotetext{
${ }^{8}$ Assuming uniform quality of firms allows to restrict the analysis to the symmetric case.

${ }^{9}$ Much of the tractability of the model rests on this assumption. In a much simpler framework without portfolio choice, Keuschnigg and Nielsen (2004) consider the case where both inputs are continuous.

${ }^{10}$ Modeling all firms symmetrically, we sidestep the problems of screening and selecting but rather focus on the moral hazard problems after a deal is struck.
} 
rate $\tau$. We also allow for a subsidy/tax $\sigma \gtrless 0$ on start-up cost $I$. Since entrepreneurs are assumed to have no own funds and cannot obtain other sources of finance, the VC must pay a price for her share that covers at least the tax inclusive start-up cost, $Q_{i} \geqslant(1+\sigma) I$. In case of success, the VC ends up with a capital gain $\left(1-s_{i}\right) V-Q_{i}$ from her share in firm $i$. When the firm fails, she registers a loss $-Q_{i}$. Assuming full loss offset, the VC's expected capital gains net of taxes from funding firm $i$ amount to $(1-\tau)\left[\left(1-s_{i}\right) V P_{i}-Q_{i}\right]$. Effort costs are intangible and, thus, cannot be deducted from the tax. To finance a portfolio of firms, the VC firm must raise a total amount of funds equal to $\sum_{i} Q_{i}$ which must be paid back from realized gains at maturity. The total investment problem of a VC is then

$$
\begin{aligned}
& \max _{n, s_{i}, Q_{i}} \quad \pi=(1-\tau) \sum_{i=1}^{n}\left[e_{i} p\left(a_{i}\right)\left(1-s_{i}\right) V-Q_{i}\right]-c(A) \\
& \text { s.t. } \quad P C_{i}^{E}: \pi_{i}^{E}=e_{i} p\left(a_{i}\right) s_{i} V+\left[Q_{i}-(1+\sigma) I\right] \geqslant l\left(e_{i}\right)+w, \\
& \quad I C_{i}^{E}: p\left(a_{i}\right) s_{i} V-\beta \geqslant 0, \\
& I C_{i}^{F}:(1-\tau) e_{i} p^{\prime}\left(a_{i}\right)\left(1-s_{i}\right) V=c^{\prime}(A), \quad i=1, \ldots, n
\end{aligned}
$$

To finance the start-up cost, the entrepreneur sells a share $1-s_{i}$ in the firm for a price $Q_{i}$, leaving her with a capital gain of $Q_{i}-(1+\sigma) I$ from this transaction. In addition, if the firm matures to production stage, she earns a share $s_{i}$ of the venture returns, giving an expected capital gain $s_{i} V P_{i}$. A separate capital gains tax on entrepreneurs is not considered since it is not required for the results of this paper. ${ }^{11}$ When considering to start the firm, the entrepreneur expects total capital gains $\pi_{i}^{E}$ which are diminished in value by an effort cost $l\left(e_{i}\right)$. She will start the firm only, if expected capital gains net of effort cost exceed the safe wage $w$ that she could earn in industry, $\pi_{i}^{E}-l\left(e_{i}\right) \geqslant w .{ }^{12}$ Condition (2.i) is the entrepreneur's participation constraint.

Once a deal is struck and the firm is started, the outside option is foregone and all initial investments are sunk. When it comes to supply effort, $Q_{i},(1+\sigma) I$ and $w$ are fixed and, thus, cannot affect the agents' choice of effort any longer. In deciding about effort, the entrepreneur is left to maximize $e_{i} p\left(a_{i}\right) s_{i} V-l\left(e_{i}\right)$ while the VC is concerned with $(1-\tau) \sum_{i} e_{i} p\left(a_{i}\right)\left(1-s_{i}\right) V-c(A)$. The entrepreneur's effort is discrete, with effort cost either $\beta$ or zero. She will supply high effort if her incentive constraint (2.ii) is satisfied. The VC's incentive constraint is given by the first order condition (2.iii) relating to managerial advice. In a static Nash equilibrium, efforts are supplied simultaneously with each party taking the other's effort as given.

\footnotetext{
${ }^{11}$ See Keuschnigg and Nielsen (2004) for a more complete analysis of taxation in a model with linear effort costs that ignores the choice of portfolio size.

${ }^{12}$ Effort cost from employment in industry is normalized to zero.
} 
Obviously, the entrepreneur's effort must always be high in equilibrium since the firm would fail with certainty and generate no revenue at all if effort were low.

When a VC fund is established and $n$ entrepreneurial firms are started, the income from each project is divided among entrepreneur, $\mathrm{VC}$ and the government. Net expected tax revenue generated by a VC fund is

$$
R=\tau \sum_{i}\left[p(a)\left(1-s_{i}\right) V-Q_{i}\right]+\sigma n I
$$

First best The social surplus $S$ is calculated by adding up the surplus of all parties,

$$
S=\pi+\sum_{i}\left(\pi_{i}^{E}-l_{i}-w\right)+R=\sum_{i} p\left(a_{i}\right) V-c(A)-(\beta+w+I) n
$$

A first best allocation obtains when efforts can be freely observed and contractually specified. It maximizes joint surplus in (4) and is characterized by the first order conditions

$$
\begin{array}{ll}
\text { (a) } a_{i}: & S_{a}=p^{\prime}(a) V-c^{\prime}(A)=0 \\
\text { (b) } n: & S_{n}=p(a) V-\beta-w-I-a c^{\prime}(A)=0
\end{array}
$$

\subsection{Advice and profit sharing}

The solution of the private equilibrium follows backward induction. At effort stage, the entrepreneur and VC simultaneously choose their joint inputs conditional on the terms of contract, as in (2.ii-iii). Having set up a fund with $n$ firms, the VC proposes at contract stage a deal $s_{i}, Q_{i}$. In doing so, she anticipates how this will subsequently influence her own and the entrepreneur's effort decision. Suppose (2.ii) holds as an inequality. Although a marginal variation of the profit share $s_{i}$ affects optimal advice $a_{i}$, this effect remains inconsequential for the VC's overall profits on account of the envelope theorem, leaving the direct effect $\partial \pi / \partial s_{i}=-(1-\tau) p\left(a_{i}\right) V<0$. The VC can thus boost her profits by offering a lower share $s_{i}$, i.e. by claiming a larger share of her own. She will do so until the entrepreneur's incentive constraint binds. With (2.ii) binding at $s_{i}$, the entrepreneur's participation constraint $(2 . \mathrm{i})$ reduces to $Q_{i}-(1+\sigma) I \geqslant w$. Obviously, the $\mathrm{VC}$ acquires her share in the firm at the lowest possible price that the entrepreneur is willing to accept. The optimal price is thus

$$
Q=(1+\sigma) I+w
$$

Why does the VC, at contract stage, give priority to reducing the profit share over cutting the purchase price? A reduction of the entrepreneur's share strengthens the VC's incentives at effort stage to add value by advising more intensively 
which raises the project's overall value to be shared among the two parties. A lower purchase price $Q$, in contrast, is sunk at effort stage and creates no such incentive. Although both measures raise VC profits, it is more profitable to cut the entrepreneur's equity share rather than paying her a lower acquisition price. ${ }^{13}$

The overall solution relating to effort and contract stages thus follows from all constraints being binding, and is recursive. Conditions (2.ii-iii) jointly determine advice and profit sharing which, in turn, yields the price $Q$ from the entrepreneur's participation (2.i). Since portfolio size enters marginal effort cost in (2.iii), the equity share and the optimal advice per firm, $s$ and $a$, must depend on portfolio size. In the first step, when a fund is established, the VC must decide upon financing and advising an optimal number $n$ of portfolio companies. In expanding the portfolio, the VC again anticipates how this affects the contract and subsequent effort levels. She then compares the extra capital gains with the additional effort cost of adding another firm to her portfolio, and finds optimal portfolio size $n$. When venture returns are high enough, it will always be worthwhile to set up a VC fund and earn non-negative profits. ${ }^{14}$

To see how a variation in portfolio size precisely affects contracts and effort levels, and to uncover some comparative static effects of tax policy, we log-linearize the conditions in (2.ii-iii). The hat notation indicates a change relative to the initial solution given by the intersection of (2.ii-iii): $\hat{a} \equiv d \ln (a)=d a / a$. To avoid a division by zero, relative changes of policy variables are defined as $\hat{\tau} \equiv d \tau /(1-\tau)$ and $\hat{\sigma} \equiv d \sigma /(1+\sigma)$. The differential of $(2 . i i-i i i)$ then yields

$$
I C^{E}: \quad \hat{s}=-(1-\theta) \hat{a}, \quad I C^{F}: \quad(\theta+\varepsilon) \hat{a}=-\hat{\tau}-\frac{s}{1-s} \hat{s}-\varepsilon \hat{n}
$$

Proposition 1 (Contract and efforts) (a) The entrepreneur's effort is high, $e=1$.

(b) A larger portfolio $n$ and a higher tax $\tau$ discourage managerial support and raise the entrepreneur's minimum required profit share according to

$$
\begin{aligned}
& \text { (a) } \hat{a}=-(\hat{\tau}+\varepsilon \hat{n}) / \Psi \\
& \text { (b) } \hat{s}=(1-\theta)(\hat{\tau}+\varepsilon \hat{n}) / \Psi \quad \Psi \equiv \theta+\varepsilon-\frac{(1-\theta) s}{1-s}>0
\end{aligned}
$$

\footnotetext{
${ }^{13}$ This minimum required equity share $s_{i}$ is, in fact, in the joint interest of the entrepreneur and VC. Comparing with the first best in (5.a), the VC should actually be full residual claimant, implying $s_{i}=0$. A higher share distorts advice and thereby reduces the cake to be shared. The closest that they can get to the first best is the minimum required equity share $s>0$ which just assures the entrepreneur's critical input, making (2.ii) binding. This is a restatement of the 'Pareto-frontier' as in Inderst and Müller (2003). With profit sharing fixed this way, any desirable sharing of the joint surplus is then achieved by a non-distortive transfer $Q_{i}-(1+\sigma) I$ from the VC to the entrepreneur.

${ }^{14}$ Kanniainen and Keuschnigg (2001b) go one step further and endogenize venture returns $V$ in industry equilibrium. Assuming free entry, they are thus able to determine the number of VC funds that an industry supports in competitive zero profit equilibrium.
} 
(c) Advice and profit sharing are independent of the start-up tax/subsidy $\sigma$. This tax increases the VC's purchase price of her stake $1-s$ by

$$
\hat{Q}=\frac{(1+\sigma) I}{Q} \hat{\sigma}
$$

Proof (a) The incentive constraint (2.ii) is fulfilled (with equality). (b) Solve the simultaneous system in (7). (c) The solution of $a$ and $s$ is determined by the incentive constraints (2.ii-iii). Since the entry tax is sunk at effort stage, it cannot influence advice and profit sharing. Since the tax inclusive start-up cost must be financed by the VC, (2.i-ii) dictate a higher purchase price. Log-linearizing (6) gives (9).

Figure 1 illustrates. ${ }^{15}$ The incentive constraints intersect twice at points A and B. By the arguments following (6), point A with a smaller value of the entrepreneur's share is the solution. At this point, the slope of the entrepreneur's incentive constraint is steeper than the VC's constraint $I C^{F}$, implying $\Psi>0$ in (8). The comparative statics are also explained. When the VC must pay a higher capital gains tax, or she has to tend a larger number of portfolio companies, the $I C^{F}$-curve shifts down. By (2.iii), the marginal cost $c^{\prime}(a n)$ of advising an individual firm increases on account of a larger portfolio, causing the VC to cut back on advice to each individual firm when she must allocate her effort to a larger number of them. A higher tax shrinks the marginal benefit of advice and thereby discourages advice for any given equity share. When the $I C^{F}$-curve shifts down, the solution moves along the $I C^{E}$-curve to the south east with less advice and a higher share to the entrepreneur. When the VC advises less, the risk to the venture increases which destroys the entrepreneur's return to effort. The entrepreneur must thus be compensated with a higher share to retain her incentives to supply the critical level of effort.

\subsection{Optimal company portfolio}

When a fund is established, the VC must decide to finance and advise an optimal number $n$ of portfolio companies. In expanding the portfolio, the VC again anticipates how this affects the contract and subsequent effort levels in later stages of the VC cycle. She then compares the extra capital gains with the additional effort cost of investing in another firm, and finds an optimal portfolio size $n$. When differentiating VC profits in (2), the envelope theorem implies that a marginal variation of advice has a zero marginal effect on her surplus on account of (2.iii). ${ }^{16}$ Imposing symmetry, one finds

$$
\pi_{n} \equiv \frac{d \pi}{d n}=(1-\tau)[(1-s) p V-Q]-a c^{\prime}-(1-\tau) n p V \frac{\partial s}{\partial n}=0
$$

\footnotetext{
${ }^{15}$ The solution is confined to some positive interval $[\underline{a}, \overline{\mathbf{a}}]$ and similarly $[\underline{s}, \overline{\mathbf{s}}]$. For example, advice per firm is limited above by the condition that the success probability in (1) cannot exceed unity. Figure 2 is developed and its properties are derived in Kanniainen and Keuschnigg (2003).

${ }^{16}$ The envelope theorem cannot be applied to $s$, however, since the entrepreneur's effort is a discrete choice variable. $I C^{E}$ forces the VC to adjust $s$ whenever she varies advice to the firm.
} 


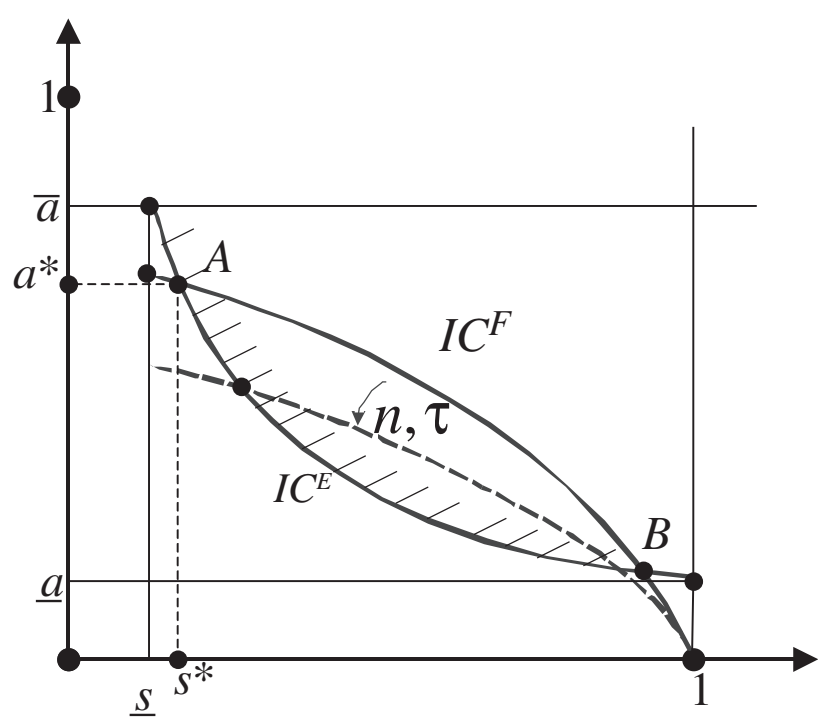

Fig. 1. Advice and profit sharing

Notation: $a$ advice, $s$ profit share, $n$ number of portfolio firms, $\tau$ tax rate, $\mathrm{IC}^{\mathrm{E}}$ and $\mathrm{IC}^{\mathrm{F}}$ incentive constraints.

To further simplify, replace $c^{\prime}$ by (2.iii), use $a p^{\prime}=(1-\theta) p$ from (1), and finally replace $p V$ by (2.ii). Write the last term as $(1-\tau) s p V \cdot \hat{s} / \hat{n}$, and use (8b) together with $(2 . \mathrm{ii})^{17}$

$$
\pi_{n}=(1-\tau)\left[z_{1}(s)-z_{2}(s)\right]=0, \quad z_{1}(s)=\frac{1-s}{s} \theta \beta-Q, \quad z_{2}(s)=\beta \frac{(1-\theta) \varepsilon}{\Psi(s)}
$$

When the VC decides upon portfolio size, she anticipates how this requires to adjust the profit share $s(n)$ and advice $a(n)$ per firm, see Proposition 1 and its illustration in Fig. 1. The variation in advice drops out of the condition on account of the envelope theorem. The variation in the profit share does not, however, but rather importantly determines portfolio size by the last term in (10). What are then the marginal benefits and costs of expanding the size of the company portfolio? According to the first term in (10), adding another company boosts the VC's overall profits by adding her share in the capital gains of this firm. On the other hand, she incurs extra managerial effort costs to advise this firm as well, raising her overall cost by the second term in (10). These two terms are consolidated to

\footnotetext{
${ }^{17}$ Noting $\Psi^{\prime}(s)=-(1-\theta) /(1-s)^{2}<0$, the sufficient condition $\pi_{n n}=\left(\partial \pi_{n} / \partial s\right)(\partial s / \partial n)<0$ is fulfilled by $\partial \pi_{n} / \partial s<0$ and $\partial s / \partial n>0$ on account of (8b). For later reference, we note that (11) implies $\theta>s$. To see this, rewrite (11) by using $\Psi$ in (8) and (2.ii), $(\theta-s)(\theta+\varepsilon) p V=\Psi Q$.
} 
give the profit creation effect (net of effort cost) which is restated in the first term $z_{1}$ of (11).

The last term in (10) is a profit destruction effect which is also restated in the second term $z_{2}$ of (11). When the VC expands her portfolio, she cuts back on advice to each individual firm as she faces progressively higher effort costs (dilution of advice). According to Fig. 1, she must cede a larger profit share to retain the incentives for the entrepreneur's critical effort. Without it, a firm would never succeed and contribute to the VC's revenues. Note, in particular, that the VC must cede higher profit shares to all her inframarginal firms as the additional advice to the marginal firm comes at the expense of all others in the portfolio. The need to share more generously with entrepreneurs subtracts from her own shares and her overall profits. This profit destruction effect becomes increasingly expensive, the larger the portfolio already is. Optimal portfolio size is found where the profit creation and destruction effects from adding another firm just balance. Figure 2 illustrates. Kanniainen and Keuschnigg (2003) derive this figure in more detail and prove that a unique optimal number of portfolio firms exists.

\section{Tax incidence}

\subsection{Profit sharing, advice, and portfolio size}

We now investigate the policy effects on the VC's overall behavior with respect to portfolio size, managerial support, and profit sharing. Note that Proposition 1 contains only partial results. When the capital gains $\operatorname{tax} \tau$, or $\operatorname{start-up} \operatorname{tax} \sigma$, induces

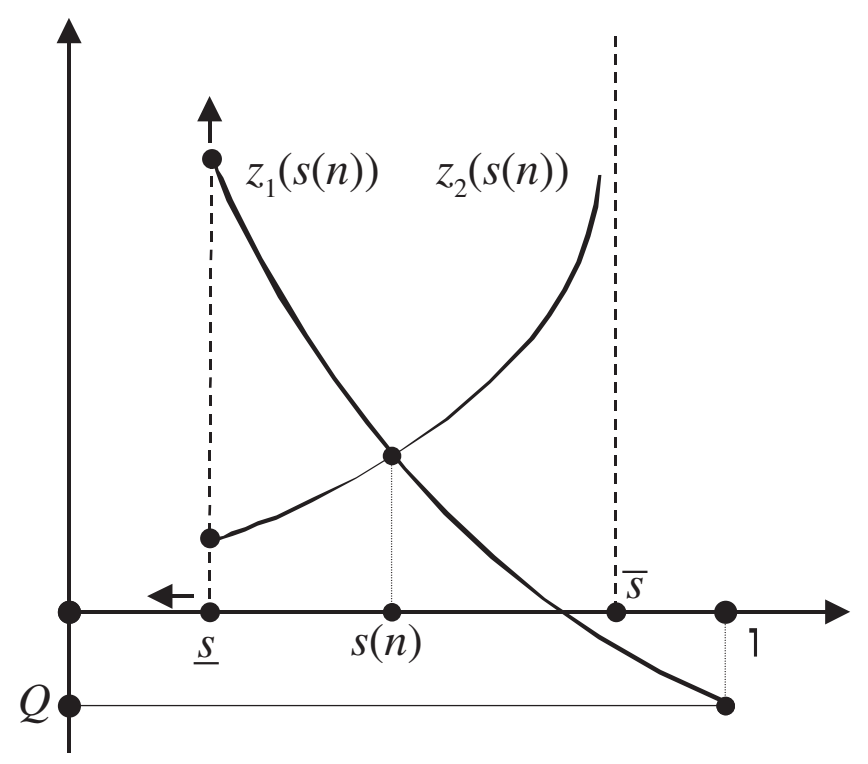

Fig. 2. Number of portfolio companies

Notation: $n$ number of portfolio firms, $s(n)$ equity share, $z_{1}$ profit creation effect, $z_{2}$ profit destruction effect, $Q$ price of share $1-s$. 
a VC to expand or consolidate her company portfolio, she will also adjust in later stages of the VC cycle the proposed profit sharing and the extent of managerial support. We have:

Proposition 2 (Comparative statics) (a) The capital gains tax $\tau$ on VC funds and the start-up tax $\sigma$ lead to smaller portfolios

$$
\hat{n}=-\frac{1}{\varepsilon} \hat{\tau}-\frac{(1+\sigma) I}{(1-\theta) \varepsilon} \frac{\Psi}{\Omega} \hat{\sigma}, \quad \Omega \equiv(\theta+\delta) \beta / s, \quad \delta \equiv \varepsilon \cdot \frac{(1-\theta)^{2} s^{2}}{(1-s)^{2} \Psi^{2}}
$$

(b) The capital gains tax $\tau$ has no effect on advice and profit sharing, the start-up $\operatorname{tax} \sigma$ boosts advice and reduces the entrepreneur's share

$$
\hat{s}=-\frac{(1+\sigma) I}{\Omega} \hat{\sigma}, \quad \hat{a}=-\frac{1}{1-\theta} \hat{s}=\frac{(1+\sigma) I}{(1-\theta) \Omega} \hat{\sigma}
$$

Proof The portfolio condition (11a) fixes a profit share $s$ which implies by (8b) the number of portfolio companies. Rewrite the portfolio condition in (11) as $\nabla=$ $z_{1}(s)-z_{2}(s)=0$, and take the differential, $d \nabla=\left[z_{1}^{\prime}(s)-z_{2}^{\prime}(s)\right] s \cdot \hat{s}-Q \hat{Q}$. Using (9) and the definitions of $z_{i}$, giving $z_{1}^{\prime}=-\theta \beta / s^{2}$ and $z_{2}^{\prime}=\varepsilon \beta(1-\theta)^{2} /\left[(1-s)^{2} \Psi^{2}\right]$, we obtain after some manipulations $d \nabla=-(1+\sigma) I \cdot \hat{\sigma}-\Omega \cdot \hat{s}$ where $\Omega$ and $\delta$ are defined as in (12). Since the portfolio condition must hold before and after the shock, we must have $d \nabla=0$ which yields the equilibrium change in the profit share given in (13). Substituting this into (8) yields the effect on advice which completes part (b). The effect on portfolio size in (12) follows by inverting (8b) and using $\hat{s}$ as in (13).

The intuition is straightforward. The start-up $\operatorname{tax} \sigma$ is sunk at effort stage and does not directly affect profit sharing and advice in (8), see Proposition 1 and its illustration in Fig. 1. Since the VC's acquisition price must suffice to finance all start-up cost, a higher tax simply inflates the VC's cost of the deal $Q$ as in (9) and, thereby, reduces the profit creation effect from the marginal firm in her portfolio. She will thus consolidate her company portfolio. With a smaller number of firms, she advises each one more intensively and, therefore, can reduce the entrepreneur's minimum required equity stake as in (13), to the benefit of her own profits. This brings the portfolio condition again into balance with a smaller number of firms. In terms of Fig. 2, the start-up tax $\sigma$ shifts down the profit creation line $z_{1}$ by raising $Q$, leading to a new intersection with smaller portfolio size $n$ and a lower share $s$.

The logic of the capital gains tax $\tau$ is somewhat different. Figure 3 illustrates the effect on portfolio size. The tax cancels from both sides of the portfolio condition and, therefore, does not involve a direct effect. This tax, however, discourages VC advice at effort stage. When advising less, the VC is forced to offer each entrepreneur a larger profit share. For a given number of firms $n$, an increase in $s$ not only 


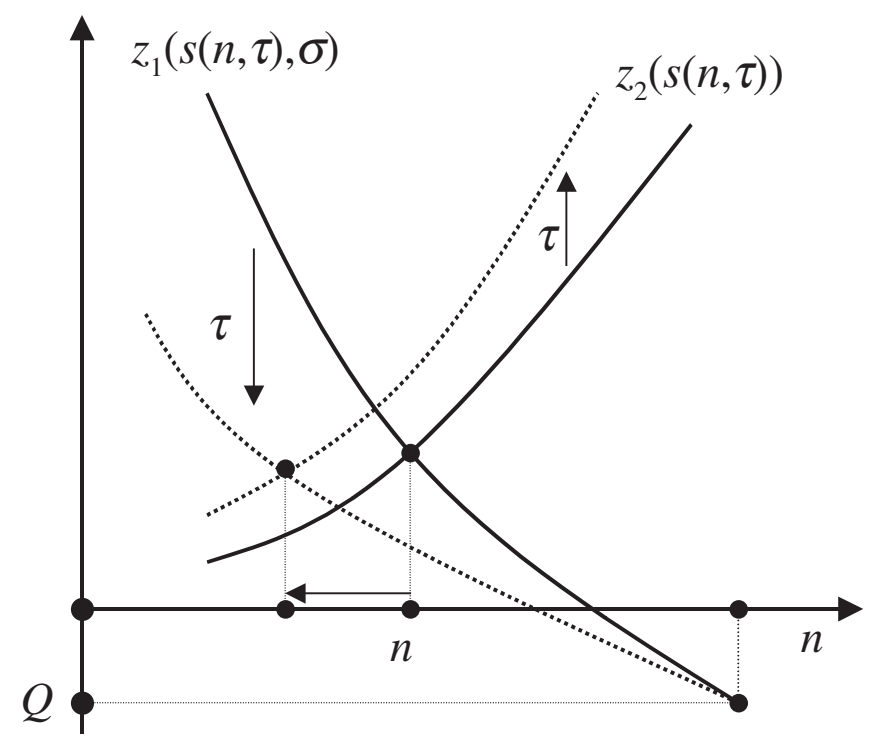

Fig. 3. Comparative statics

Notation: $n$ number of portfolio firms, $s$ equity share, $\tau$ tax rate, $\sigma$ start-up tax, $z_{1}$ profit creation effect, $z_{2}$ profit destruction effect, $Q$ price of share $1-s$.

reduces the VC's share of capital gains in the marginal firm, thereby eroding the profit creation effect $z_{1}[s(n, \tau)]$, but of all other firms in her portfolio as well, thereby inflating the profit destruction effect $z_{2}[s(n, \tau)]$. Holding $n$ fixed, the profit creation line shifts down while the profit destruction line shifts up since $z_{1}^{\prime}<0<z_{2}^{\prime}$ holds and since $s$ increases in $\tau$ by (8b). The new intersection occurs at lower $n$. Consequently, the VC consolidates her portfolio as in (12). With a smaller portfolio, she advises more intensively again which neutralizes the direct effect of the tax on advice and profit sharing, leaving a zero overall impact as in (13). This feedback effect is recognized in Fig. 1 where the reduction in portfolio size shifts back VC's incentive constraint $I C^{F}$ into its original position. The appendix also calculates how tax policy affects VC profits. Not surprisingly, both taxes depress profits as in (A.1).

\subsection{Optimal taxation of venture capital}

Welfare is equal to joint surplus in (4). Joint surplus consists of the consolidated value of VC and entrepreneurial income, net of effort costs. In particular, it is independent of the share $s_{i}$ with which the parties split profits among them in private equilibrium. Policy affects welfare only via its effects on the level of managerial support and the size of the VC's portfolio of companies. According to (4), the change in welfare is

$$
d S=n a S_{a} \cdot \hat{a}+n S_{n} \cdot \hat{n}
$$


If market equilibrium were first best such that conditions (5) would hold, $S_{a}=S_{n}=0$, policy could not improve upon VC investments in the private equilibrium. Rather than aiming at the joint surplus, however, each party considers only its own share $s_{i}$ and $1-s_{i}$ of a project's revenues, less its private costs, taking the other party's actions as given. The corresponding private and social margins in (2.iii), (10), and (5) are thus quite different. Using (2.iii) to replace $c^{\prime}$, we have

$$
S_{a}=[1-(1-\tau)(1-s)] \cdot p^{\prime}(a) V
$$

The optimal capital gains tax $\tau^{*}$ that induces the VC to supply the first best level of advice, is negative and thus corresponds to a revenue subsidy. It satisfies $\left(1-\tau^{*}\right)(1-s)=1$ and thus reduces the square bracket to zero. With the optimal subsidy in place, the private and social conditions in (2.iii) and (5.a) are identical. In the untaxed equilibrium, however, policy would contribute to higher welfare if it encourages more advice, $d S=A S_{a} \cdot \hat{a}>0$ since $S_{a}=s p^{\prime}(a) V>0$ in this case. Advice is too low since the VC calculates a private return to advice that falls short of the social return by a factor $1-s$. In supplying a marginal unit of advice to a portfolio company, the VC bears the entire effort cost but appropriates only a part $1-s$ of the social return $p^{\prime}(a) V$. The other part $s p^{\prime}(a) V$ spills over to the entrepreneur who requires a minimum incentive compatible profit share to supply her critical effort. The optimal revenue subsidy compensates for this spillover by grossing up the VC's share until she gets $100 \%$ of the social returns to her costly consulting activity, $\left(1-\tau^{*}\right)(1-s)=1$. Only with this subsidy can the VC act as if she were full residual claimant while the entrepreneur also gets her incentive compatible profit share. ${ }^{18}$ Of course, this subsidy is only implicitly determined since, by (8), the equilibrium share $s$ also depends on it.

To identify the distortion with respect to the VC's choice of portfolio size, it is useful to calculate from (3) the tax revenue per start-up firm, $r \equiv R / n$, as in (16a). By (2.iii), $a c^{\prime}=(1-\tau)(1-s)(1-\theta) p V$. Replacing this in (10) shows that the tax base is equal to $(1-s) p V-Q=(1-s)(1-\theta) p V+z_{2}$, where $z_{2}$ is the gross profit destruction effect. Thus, the tax revenue per project is also written as in (16b)

$$
\begin{aligned}
& \text { (a) } r=\sigma I+\tau[(1-s) p V-Q] \\
& \text { (b) } r=\sigma I+\tau\left[(1-s)(1-\theta) p V+z_{2}\right]
\end{aligned}
$$

Using (6), (2.ii), and the definitions of $r$ and $S_{n}$ in (16a) and (5), the private portfolio condition in (10) can be restated as

$$
\pi_{n}=S_{n}-\left[r+(1-\tau) z_{2}\right]=0
$$

\footnotetext{
${ }^{18}$ Since the entrepreneur's effort is critical, it cannot be underprovided. The entrepreneur always gets the minimum required equity share which prevents her from shirking. If both efforts were variable, then also the entrepreneur's effort would be inefficiently low in private equilibrium. Optimal policy would then need to subsidize also the entrepreneur's revenue, as is shown in the revised version of Keuschnigg and Nielsen (2004). These authors do not consider the impact of taxation on portfolio choice.
} 
Accordingly, the private and social returns to expanding VC portfolio size differ for two reasons. First, the private portfolio decision is distorted by the presence of a profit destruction effect. Since the cost of total managerial effort increases progressively, the VC tends to advise each individual firm less intensively when she adds yet another company to her portfolio of firms. When receiving less advice, entrepreneurs must expect a smaller success probability of the firm and therefore claim a larger share $s$ of the venture return to compensate for their own critical effort. Since this holds for all firms in the portfolio, the VC earns less on each firm. From a social perspective, however, this profit destruction effect is a mere redistribution between VC and entrepreneur. It is therefore absent in the social condition (5). Second, the incentive to finance and advise a larger number of portfolio firms is also impaired when projects carry a larger tax burden $r$. Again, this private cost is absent from the social condition since it only redistributes towards the taxpayer.

Proposition 3 (Optimal policy) (a) In private equilibrium, VC portfolio size and managerial support per firm are too small. A small capital gains tax on VC profits involves first order welfare losses while a small start-up tax/subsidy yields a zero welfare effect.

(b) The optimal policy replaces the capital gains tax with a revenue subsidy but levies a tax on start-up cost. It achieves the first best. The optimal tax/subsidy rates are

$$
\tau^{*}=-\frac{s}{1-s}<0, \quad \sigma^{*}=\frac{(\theta-s) z_{2}}{(1-s) \varepsilon I}>0
$$

(c) The optimal policy looses revenue.

Proof (a) When $\tau=\sigma=r=0$, (15) and (17) yield coefficients $S_{a}=s p^{\prime} V>0$ and $S_{n}=z_{2}>0$. Consequently, joint surplus in (14) increases with more advice $\hat{a}>0$ and larger portfolio size $\hat{n}>0$. Substituting $S_{a}=p^{\prime} s V, S_{n}=z_{2}$ and (12-13) into (14) yields [also use (2.ii), $z_{2}=(1-\theta) \varepsilon \beta / \Psi$ and $a p^{\prime}=(1-\theta) p$ ]

$$
d S=n z_{2} \cdot \frac{-1}{\varepsilon} \hat{\tau}<0, \quad d S=n \operatorname{sap}^{\prime} V \cdot \frac{I}{(1-\theta) \Omega} \hat{\sigma}+n z_{2} \cdot \frac{-I \Psi}{(1-\theta) \varepsilon \Omega} \hat{\sigma}=0
$$

(b) Policy is optimal and achieves the first best when the welfare gains (increase in joint surplus) from a marginal variation of tax rates are zero. By (14), one must have $S_{a}=S_{n}=0$. Setting the square bracket in (15) to zero yields the optimal revenue subsidy $\tau^{*}$. By (17), $S_{n}=r+\left(1-\tau^{*}\right) z_{2}$. Substituting (16b), using (18) and (2.ii) as well as $z_{2}=(1-\theta) \varepsilon \beta / \Psi$, we have $S_{n}=\sigma I-(1-\theta) s p V+z_{2}$ or $S_{n}=\sigma I-(\theta-s) z_{2} /[(1-s) \varepsilon]=0$. This yields the optimal start-up tax $\sigma^{*}$ in (18) where $\theta>s$ was shown in fn.16 relating to (11). (c) The optimality condition $S_{n}=r+\left(1-\tau^{*}\right) z_{2}=0$ implies $r=-\left(1-\tau^{*}\right) z_{2}<0$.

Although it is rather obvious that two instruments suffice to target two distortions, the specific role of the revenue subsidy and the start-up tax are not easily anticipated. Somewhat surprisingly, Proposition 2 revealed that a revenue subsidy fails to boost the equilibrium level of VC advice. Although it directly 
strengthens the incentive to advise [set $\hat{\tau}<0$ in (8)], there is a second countervailing effect. The revenue subsidy is the reverse experiment in Fig. 3 and thus leads a VC to include more firms in her portfolio which crowds out the extent of advice per firm (dilution of advice), leaving an overall effect of zero. In the end, the revenue subsidy only succeeds to expand the portfolio of firms beyond the efficient size but is unable to boost advice per firm. It needs to be complemented by a startup tax which restricts portfolio size to the efficient level. As the VC consolidates her portfolio, she advises each firm more intensively as is desired for efficiency. To sum up, the revenue subsidy alone would be counterproductive because it tends to encourage portfolio expansion to such an extent that it would completely crowd out the direct incentives for more advice. Only the combined package succeeds to boost advice via the incentive effects of the revenue subsidy while the simultaneous use of the start-up tax correctly defines a smaller net subsidy per project that prevents an overly large portfolio expansion. This net subsidy per project is reflected in the fact that the optimal policy is revenue loosing; see part (c) of the proposition.

Starting from an untaxed position, policy moves the equilibrium towards the first best by adjusting rates according to $\hat{\tau}<0<\hat{\sigma}$. According to (12)-(13), this obviously boosts advice. The effects on portfolio size tend to offset each other, however. For completeness, we now show that the optimal policy indeed involves larger portfolio size as is suggested by (14). In moving towards the first best, we must set the policy variables as $\hat{\sigma}=\sigma^{*}$ and $\hat{\tau}=\tau^{*}{ }^{19}$ Recalling (18), using the definition of $z_{2}$ and $\Omega$, and substituting into (12) yields $\hat{n}=s /((1-s) \varepsilon)(s+\delta) /$ $(\theta+\delta)>0$. Moving towards the optimal policy thus boosts advice and portfolio size. Finally, it is worth noting that the optimal policy looses revenue but is at least partly self-financing since the revenue from the start-up tax is available to pay for part of the subsidy cost.

\subsection{Robustness of results}

For the sake of simplicity, the present model necessarily omits a number of aspects of VC investing that might potentially modify the results to some extent. First, all entrepreneurial projects are assumed identical. Allowing for project heterogeneity would introduce the problem of selection among firms of unknown quality, and VCs indeed spend, besides their mentoring activity, a considerable amount of time on screening and project selection (Kaplan and Strömberg, 2000). However, adverse selection may give rise to both over and underinvestment at the same time so that no clear cut policy prescription seems to emerge (see Hellmann and Stiglitz, 2000, for a generalized model and Boadway and Tremblay, 2003, for a review of public finance implications). Future research might explore the interaction of screening and selection on the one hand and advising subject to moral hazard on the other hand.

\footnotetext{
${ }^{19}$ The relative policy change is $\hat{\sigma} \equiv d \sigma /(1+\sigma)=d \sigma$ if one starts at an untaxed state with $\sigma=0$ initially. Considering the change from zero to the optimal values gives $\hat{\sigma}=d \sigma=\sigma^{*}$ and $\hat{\tau}=d \tau=\tau^{*}$.
} 
The present model is partial equilibrium in nature where the project value $V$ available in case of success remains exogenous. Expected venture returns $p V$ are endogenous since the success probability depends on effort. Embedding this framework in a model that endogenously explains venture returns $V$ as in Kanniainen and Keuschnigg (2002) would introduce feedback effects of tax policy on effort and advice by its equilibrium impact on venture returns. The two sector general equilibrium analysis in Keuschnigg and Nielsen (2004) shows, however, that these feedback effects are unlikely to turn around the partial equilibrium effects of taxes.

In assuming simultaneous choice of entrepreneurial effort and VC advice, the present model allows no more than straight equity finance as the optimal financial contract and cannot rationalize the use of convertible instruments which are prevalent in the US (Sahlman, 1990, and Kaplan and Strömberg, 2003). However, common equity is indeed the most frequently used form of finance in Europe (Cumming, 2002; Bascha and Walz, 2001; and Schwienbacher, 2002) and Canada (Cumming, 2001a) while convertibles are used quite infrequently. Moreover, Gilson and Schizer (2002) argue that there is a significant tax bias in favor of convertible preferred securities in the US. Cumming (2001b) finds that even US based VCs rely much less on convertibles if they invest in Canada where there is no such tax bias (as reported by Sandler, 2001). Given the tax explanation proposed for the US and the evidence for other countries seems to justify the use of straight equity in a simple model that focusses on the interaction of portfolio choice, advice and the impact of taxes.

It must be mentioned though that the underinvestment result is probably somewhat reduced if one allows for more flexible financial contracting. Indeed, the industry has developed a number of contractual instruments to address some prevalent incentive problems in VC investing that are not considered in the present model: staging, syndication, covenants, contingencies, control rights etc. (see Lerner, 1994; Gompers, 1995; Gompers and Lerner, 1996; Kaplan and Strömberg, 2003; and the theoretical literature mentioned in footnote 5). Kaplan and Strömberg (2001, p. 427) emphasize, however, that cash flow and control rights are more like complements rather than substitutes. Schmidt (2003) shows that convertible securities can, in principle, help to achieve even a first best equilibrium with double moral hazard which would eliminate our underinvestment result. However, his result hinges critically on the fact that efforts are never required simultaneously but only sequentially (see Schmidt, 2003, Section III.G). This paper stresses the fact that the entrepreneur's effort is critical throughout the company's life. In reality, most business failures are ultimately due to some entrepreneurial management mistake. When the joint efforts of entrepreneurs and financier overlap and are required simultaneously, the possible advantage of convertible securities relative to straight equity is reduced. We conclude that a richer and more dynamic modeling of the relationship between VCs and entrepreneurs can rationalize more flexible financial instruments and will reduce to some extent, though not eliminate, the underinvestment result reported in this paper. 
The analysis of taxes in richer models of VC investing seems a promising field for future research.

Furthermore, the present model yields testable implications that could be investigated in future empirical work. The key element driving the results is the quality quantity trade-off in VC investing. Larger portfolios tend to undermine the quality of advice. The present framework is based on Kanniainen and Keuschnigg (2002) who have also endogenized firm values. In particular, they were able to show how demand and supply side shocks determine the industry's adjustment much in line with Lerner's (2002) empirical account of the boom and bust periods in VC finance. According to Lerner, the impact of VC on innovation is some $15 \%$ lower during boom periods compared to normal industry periods. In Kanniainen and Keuschnigg's (2002) framework, the number of VC firms is fixed in the short-run so that booming demand with high venture returns leads VC firms to finance each a larger company portfolio which undermines the quality of advice. When the industry returns to a more normal equilibrium with free entry, the managerial resource constraint relaxes, leading to smaller portfolios but more intensive involvement with each firm. This replicates the empirical finding of Lerner and points to the importance of the quality versus quantity trade-off.

Following Cumming (2001a), further empirical work should try to verify with firm specific data the inverse relationship between portfolio size and measures of managerial support. VC firms with a larger number of portfolio companies should be less closely involved with their firms. In particular, there is almost no empirical evidence available on how VC firms respond to taxes. Poterba (1989) and Gompers and Lerner (1998) have shown that a lower capital gains tax might encourage entrepreneurial entry but have not shed any light on how taxes affect the incentives of VC funds. Proposition 2 yields the sharp prediction that lower taxes or tax exemptions for VC funds should lead to larger portfolios. Because larger portfolios crowd out advice, such tax relieve should not significantly affect the quality of VC investments in terms of managerial support. For the same reason, subsidies to the cost of capital investments (negative start-up taxes) should lead to larger portfolios but less intensive mentoring activities.

\section{Conclusions}

Young entrepreneurial firms are an important source of innovation and growth. Yet these high tech firms face considerable obstacles in the early phase of business development. Entrepreneurs are often technologically competent but commercially inexperienced. Compared to the capital needs of a fast growing company, they have only negligible own resources to finance start-up investment costs. Due to the high technological and managerial risks as well as the existence of severe informational asymmetries, outside risk capital is difficult if not impossible to obtain from traditional sources of finance. VCs, however, have specialized in financing young, innovative firms. They have money, managerial know-how, and industry knowledge. Given their managerial expertise, they are better able to understand and 
appropriately deal with the informational and incentive problems of young firms. They not only provide finance but also advise in matters of business strategy, provide contacts to suppliers and clients, help to build a company's human resource base, and generally support the professionalization of young firms. In short, an experienced VC can importantly enhance the prospects of start-up firms.

Yet the value added of venture capital is not a guaranteed matter. The VC's managerial support is a complementary input to the entrepreneur's more technological contribution. Team production with profit sharing tends to create important incentive problems. In financing a portfolio of firms, VCs additionally face a trade-off between the number of portfolio companies and the amount of advice allocated to each individual venture. This paper presented a model of a VC with a portfolio of firms and argued that VC support as well as the number of firms in a VC portfolio tend to be too low in private equilibrium. In this situation, a capital gains tax on VC funds is found to be particularly harmful as it tends to impair the incentives for advice and also leads to smaller portfolios. It thus aggravates a preexisting market distortion in both dimensions. Tax policy, however, can be appropriately designed to foster a more active and, thus, more efficient style of VC investment. The optimal policy was found to be a performance related revenue subsidy, or negative capital gains tax, combined with a non-performance related tax on start-up investment cost. The revenue subsidy boosts advice but, at the same time, expands portfolio size and thereby crowds out advice per firm again. The revenue subsidy must thus be combined with a start-up tax in order to arrive at a more moderate net subsidy per project to prevent an overly large portfolio expansion. The policy even succeeds to move the private equilibrium to a first best optimum.

How does the analysis connect to real world taxation of the VC industry? A VC fund is usually a corporate firm that holds substantial equity claims in a number of start-up companies. Dividend payments to the VC fund or capital gains on the equity holdings are in principle subject to the corporate tax which would be the tax rate $\tau$ in our model. In Switzerland and Germany, however, and probably in many other countries as well, dividends and capital gains from substantial holdings in other firms (a share of more than $5 \%$ is considered as substantial in Switzerland) accrue tax free to the parent company. Only when the VC firm distributes the consolidated gains and dividends from its operations to its owners, it must take account of taxes on the suppliers of capital. These may partly be tax free institutions such as pension funds, or persons subject to capital gains taxation, or other companies such as banks, which may again get these returns as income from substantial holdings free of taxes. In any case, if such taxes are applied, they basically increase the cost of capital to the VC fund and, thus, can be subsumed under the start-up tax $\sigma$. If the income from substantial holdings in other firms is tax free at the company level $(\tau=0)$, this tax arrangement already removes important disincentives for managerial support. If the VC fund's distributions to its owners is subject to taxes, such taxation increases the cost of funds and works much like a start-up tax $\sigma$. According to part (a) of Proposition 3, a start-up tax 
involves a zero first order welfare effect and should not be very harmful. The optimal policy even calls for a positive start-up tax combined with a revenue subsidy. A revenue subsidy to $\mathrm{VC}$ funds seems not a realistic and practical tax reform proposal. However, exempting from the corporate income tax the income received from substantial holdings in other companies would at least remove an important impediment to VC investments, compared to full taxation of such income.

\section{Acknowledgements}

The paper was presented at the CESifo Venice Summer Institute, The Changing Organization of Labour, 2002. I appreciate constructive comments by seminar participants and, in particular, by V. Kanniainen, S.B. Nielsen, and the discussant C. Lülfesmann. I am indebted to two anonymous referees for very detailed comments which helped to further improve the paper.

\section{References}

Aghion, P. and Tirole, J. (1994). 'The Management of innovation', Quarterly Journal of Economics, 109, 1185-209.

Bascha, A. and Walz, U. (2001). 'Financing practices in the German venture capital industry: an empirical assessment', Discussion Paper, Department of Economics, University of Tübingen.

Bergemann, D. and Hege, U. (1998). 'Venture capital financing, moral hazard, and learning', Journal of Banking and Finance, 22, 703-35.

Boadway, R. and Tremblay, J.-F. (2003). 'Public economics and start-up entrepreneurs', paper prepared for CESifo conference on Venture Capital, Entrepreneurship and Public Policy, Munich.

Bottazzi, L. and Da Rin, M. (2002). 'Venture capital in europe: euro.nm and the financing of european innovative firms', Economic Policy, 34, 231-69.

Casamatta, C. (2003). 'Financing and advising: optimal financial contracts with venture capitalists', Journal of Finance, 58, 2059-85.

Cornelli, F. and Yosha, O. (2003). 'Stage financing and the role of convertible securities', Review of Economic Studies, 70, 1-32.

Cumming, D.J. (2001a). 'Determinants of venture capital portfolio size: empirical evidence', Discussion Paper, University of Alberta School of Business, Edmonton.

Cumming, D.J. (2001b). 'United States venture capital financial contracting: evidence from investments in foreign securities', Discussion Paper, University of Alberta School of Business, Edmonton.

Cumming, D.J. (2002). 'Contracts and exits in venture capital finance', Discussion Paper, University of Alberta School of Business, Edmonton.

Cumming, D.J. and MacIntosh, J.G. (2002). 'Canadian labour sponsored venture capital corporations: bane and boon?', in A. Ginsberg and I. Hasan (eds), Venture Capital, Entrepreneurship and Growth, Elsevier Science, Amsterdam. 
Gilson, R.J. and Schizer, D.M. (2002). 'Understanding venture capital structure: a tax explanation for convertible preferred stock', Discussion Paper, Columbia Law School, New York. Gompers, P.A. (1995). 'Optimal investment, monitoring, and the staging of venture capital', Journal of Finance, 5, 1461-89.

Gompers, P. and Lerner, J. (1996). 'The use of covenants: an empirical analysis of venture partnership agreements', Journal of Law and Economics, 39, 463-98.

Gompers, P.A. and Lerner, J. (1998). 'What drives venture capital fundraising?', Brookings Papers on Economic Activity - Microeconomics, 149-92.

Gompers, P.A. and Lerner, J. (1999). The Venture Capital Cycle, MIT Press, Cambridge, MA.

Gordon, R.H. (1998). 'Can high personal tax rates encourage entrepreneurial activity?', IMF Staff Papers, 45, 49-80.

Hellmann, T. (1998). 'The allocation of control rights in venture capital contracts', Rand Journal of Economics, 29, 57-76.

Hellmann, T. and Puri, M. (2000). 'The interaction between product market and financing strategy: the role of venture capital', Review of Financial Studies, 13, 959-84.

Hellmann, T. and Puri, M. (2002). 'Venture capital and the professionalization of start-up firms', Journal of Finance, 57, 169-97.

Hellmann, T. and Stiglitz, J. (2000). 'Credit and equity rationing in markets with adverse selection', European Economic Review, 44, 281-304.

Holmström, B. (1982). 'Moral hazard in teams', Bell Journal of Economics, 13, 324-40.

Inderst, R. and Müller, H.M. (2003). 'The effect of capital market characteristics on the value of start-up firms', Journal of Financial Economics, forthcoming.

Kanniainen, V. and Keuschnigg, C. (2002). 'Start-up investment with scarce venture capital support', Journal of Banking and Finance, forthcoming.

Kanniainen, V. and Keuschnigg, C. (2003). 'The optimal portfolio of start-up firms in venture capital finance', Journal of Corporate Finance, 9, 521-34.

Kaplan, S.N. and Strömberg, P. (2000). 'How do venture capitalists choose investments?', Discussion Paper, Department of Economics, University of Chicago.

Kaplan, S.N. and Strömberg, P. (2001). 'Venture capitalists as principals: contracting, screening, and monitoring', American Economic Review, 91, 426-30.

Kaplan, S.N. and Strömberg, P. (2003). 'Financial contracting theory meets the real world: an empirical analysis of venture capital contracts', Review of Economic Studies, 70, 281-315.

Keuschnigg, C. and Nielsen, S.B. (2001). 'Public policy for venture capital', International Tax and Public Finance, 8, 557-72.

Keuschnigg, C. and Nielsen, S.B. (2003). 'Tax policy, venture capital, and entrepreneurship', Journal of Public Economics, 87, 175-203.

Keuschnigg, C. and Nielsen, S.B. (2004). 'Start-ups, venture capitalists, and the capital gains tax', Journal of Public Economics, 88, 1011-42.

Kortum, S. and Lerner, J. (2000). 'Assessing the contribution of venture capital to innovation', Rand Journal of Economics, 31, 674-92.

Lerner, J. (1994). 'The syndication of venture capital investments', Financial Management, 22, 16-27. 
Lerner, J. (2002). 'Boom and bust in the venture capital industry and the impact on innovation', Federal Reserve Bank of Atlanta Economic Review, 2002(4), 25-39.

Lülfesmann, C. (2001). 'Team production, sequential investments, and stochastic payoffs', Journal of Institutional and Theoretical Economics, 157, 430-42.

Neher, D. (1999). 'Staged financing: an agency perspective', Review of Economic Studies, 66, 255-74.

Poterba, J.M. (1989). 'Capital gains tax policy toward entrepreneurship', National Tax Journal, 42, 375-89.

Repullo, R. and Suarez, J. (1999). 'Venture capital finance: a security design approach', Discussion Paper, CEMFI, Madrid.

Sahlman, W.A. (1990). 'The structure and governance of venture capital organizations', Journal of Financial Economics, 27, 473-521.

Sandler, D. (2001). 'The tax treatment of employee stock options: generous to a fault', Canadian Tax Journal, 49, 259-302.

Schmidt, K.M. (2003). 'Convertible securities and venture capital finance', Journal of Finance, 58, 1139-66.

Schwienbacher, A. (2002). 'An empirical analysis of venture capital exits in Europe and in the United States', Discussion Paper, Department of Economics, University of Namur.

\section{Appendix}

The appendix calculates the effects of taxes on VC profits. Take the differential of (2). The effects via $a$ and $n$ can be ignored on account of the envelope theorem. Using (9) and (2.ii) yields

$$
d \pi=-(1-\tau) n \cdot[((1-s) p V-Q) \hat{\tau}+(1+\sigma) I \hat{\sigma}+\beta \hat{s}]
$$

Use (2.ii) to write the profit creation effect as $z_{1}=(1-s) \theta p V-Q$ and rewrite the coefficient of $\hat{\tau}$ after expanding by $(1-s) p V \theta$. Substitute $\hat{s}=-(s(1+\sigma) I) /(\beta(\theta+\delta)) \hat{\sigma}$ from (12)-(13), collect terms and note that $\theta>s$ as noted in the footnote relating to (11). This shows that both taxes depress profits

$$
\frac{d \pi}{(1-\tau) n}=-\left[z_{1}+(1-\theta)(1-s) p V\right] \cdot \hat{\tau}-\frac{\theta-s+\delta}{\theta+\delta}(1+\sigma) I \cdot \hat{\sigma}
$$

